\title{
Drain Detectives: Lessons Learned from Citizen Science Monitoring of Beach Drains
}

DARREN COTTAM

CAMILLE MCGUIRE

DAVID MOSSOP (D)

GERALDINE DAVIS

JULIAN DONLEN

KIRSTEN FRIEND

BRAD LEWIS

EMILY BOUCHER

*Author affiliations can be found in the back matter of this article
HARISH KIRUBAKARAN

REBECCA GOULDING

DUSAN JOVANOVIC (D)

DAVID MCCARTHY (D)

APRIL SEYMORE (1)

CAROLINE MARTINO

KELLY ZUCCALA

\section{] $\mathrm{u}[$ ubiquity press}

CORRESPONDING AUTHOR:

\section{Darren Cottam}

Environment Protection

Authority Victoria, AU

darren.cottam@epa.vic.gov.au

\section{KEYWORDS:}

citizen scientist; signs; sensors; beach drains; microbial water quality; engagement

\section{TO CITE THIS ARTICLE:}

Cottam, D, McGuire, C, Mossop, D, Davis, G, Donlen, J, Friend, K, Lewis, B, Boucher, E, Kirubakaran, H, Goulding, R, Jovanovic, D, McCarthy, D, Seymore, A, Martino, C and Zuccala, K. 2021. Drain Detectives: Lessons Learned from Citizen Science Monitoring of Beach Drains. Citizen Science: Theory and Practice, 6(1): 20, pp. 1-12. DOI: https://doi. org/10.5334/cstp.383 


\section{INTRODUCTION}

Stormwater drains are a common feature at most urban beaches around the world. On Port Phillip Bay's coastline, there are more than 300 drains, many at popular beaches in the Greater Melbourne area. During and following rain, stormwater pollution from drains is known to impact microbial water quality at Port Phillip Bay beaches (epa. vic.gov.au). Dry-weather flows (i.e., flows from drains not related to rain) are also possible. These are more difficult to monitor because, unlike stormwater pollution, they cannot be predicted and may involve smaller flows that can impact water quality at the beach.

Environment Protection Authority Victoria (EPA) currently monitors microbial water quality at beaches, which is useful for ambient monitoring of long-term water quality. Weekly monitoring of microbial indicators (enterococci, E. coli) of faecal pollution has provided EPA with a good understanding of the impacts stormwater pollution has on beaches during summer.

However, there are limitations to this type of monitoring in regard to its sensitivity to dry-weather pollution. The frequency of monitoring and the turnaround times for analysis can also limit investigation into high microbial results. Current water quality monitoring may not be sensitive enough to detect dry-weather flows at nearby drains, as these flows are likely smaller than larger stormwater pollution plumes during and after rain. Although smaller, with more localised impact, dry-weather flows may still have microbial levels that present risks to Bay users who swim near the drain outlets. With sampling conducted once a week, the spatial and temporal extent of dry-weather pollution from drain flows is also unknown. Long-term data indicates that enterococci can be high (> 200 enterococci/100 $\mathrm{mL}$ ) during dry weather, but the cause can be difficult to establish. The 24-hour turnaround time for analysis often means the pollution, and the evidence of the source, is no longer present by the time sample results are available.

Citizen science has become increasingly popular for stand-alone environmental monitoring programs or to support existing monitoring (Pocock et al. 2017; Roger, Turak, and Tegart 2019). Citizen science offers a potential low-cost method to increase the spatial and temporal scale of environmental monitoring. This low-cost expansion of monitoring is otherwise not available through traditional monitoring approaches (Capdevila et al. 2020). The addition of citizen science to environmental monitoring is also valuable in getting public support and participation for environmental science (Jalbert and Kinchy 2015; Capdevila et al. 2020).
Citizen science is currently used in a variety of ways in Australia and overseas to monitor water quality or pollution in waterways and coastal waters. Citizen science for water quality monitoring in Australia has mostly been in the form of citizen scientists collecting water quality samples or performing in-situ measurements, and recording data through a website (e.g., Waterwatch Australia, EstuaryWatch, StreamWatch).

The use of smartphones and data-collection platforms in citizen science has become increasingly common for a broad range of environmental monitoring (Jones et al. 2018; Jovanovic, Carrion, and Brovelli 2019; Capdevila et al. 2020). It has allowed much greater participation in citizen science by the community (Graham, Henderson, and Schloss 2011; Safford and Peters 2017; Compas and Wade 2018), translating into greater spatial and temporal reach (Jones et al. 2018; Capdevila et al. 2020; Roger et al. 2020). As well as addressing data gaps from a quantitative perspective, citizen science data may also enhance monitoring by allowing collection of different types of data not available through traditional monitoring.

Continuous, real-time water quality sensors installed in drains provide valuable data on the water quality and change in depth of flows moving through drains. However, there are limitations to what this data can provide. Citizen science monitoring using a smartphone and a data collection platform can be used to collect data that sensors in drains cannot monitor, such as the size of flow at the outlet, the colour of the water, the presence and extent of continuous background flows, and whether flows are entering a water body.

There is a range of approaches for using citizen science, smartphones, and data collection platforms for collecting data to complement sensors or existing monitoring. The hands-on approach of training citizen scientists and supporting them to monitor the environment is common (Storey et al. 2016; Farnham et al. 2017; Church et al. 2018; Hegarty et al. 2021). Alternatively, crowd sourcing through social media or signage is another approach that is becoming more popular, with potentially greater reach than only using trained citizen scientists (Jones et al. 2018; Hartley et al. 2019: Lowry et al. 2019).

A two-year Drain Detectives project (2018-2020) trialled innovative, low-cost approaches such as citizen science and open-source sensors to monitor dry-weather flows in drains. The citizen science monitoring involved the use of smartphones by the community to report flows at signed drains and by trained citizen scientists who monitored a broader range of parameters at multiple drains at a beach. The data was used to better understand and inform management of stormwater drains posing the highest risk 
to beach water quality in Port Phillip Bay. The project was delivered in partnership with three councils (Bayside City Council, Kingston City Council, and Mornington Peninsula Shire Council), two water corporations (South East Water and Melbourne Water), Monash University, Port Phillip EcoCentre, and the local community.

This case study identifies some key learnings from the Drain Detectives project, with the aim of offering insights and learnings that can be used in similar projects, or more broadly as part of the design and delivery of citizen science projects.

\section{METHODS}

An overview is provided of the locations of monitored drains and the methods used to monitor beach drains. More information on Drain Detectives methods is available at epa.vic.gov.au.

\section{SELECTION OF DRAINS}

As part of EPA's Beach Report program (epa.vic.gov.au), short- and long-term microbial water quality results indicated that enterococci levels could be impacted during dry weather at some of the 36 Port Philip Bay sites monitored annually. Ten of these beach sites were selected for Drain Detectives monitoring (Figure 1).

In 2018-19, sixteen drains at five beaches were monitored. One drain per beach had signage installed, while citizen scientists monitored between two to four drains at each beach. In 2019-20, ten drains at ten beaches were monitored, with sensors installed at all beaches and signage and citizen scientists continuing to monitor the five beaches from year one.

The number of drains monitored per beach by trained citizen scientists was reduced in year two from monitoring between two to four drains per beach to just one per beach (i.e., five drains across five beaches). This was based on a review of year-one monitoring, which identified that there

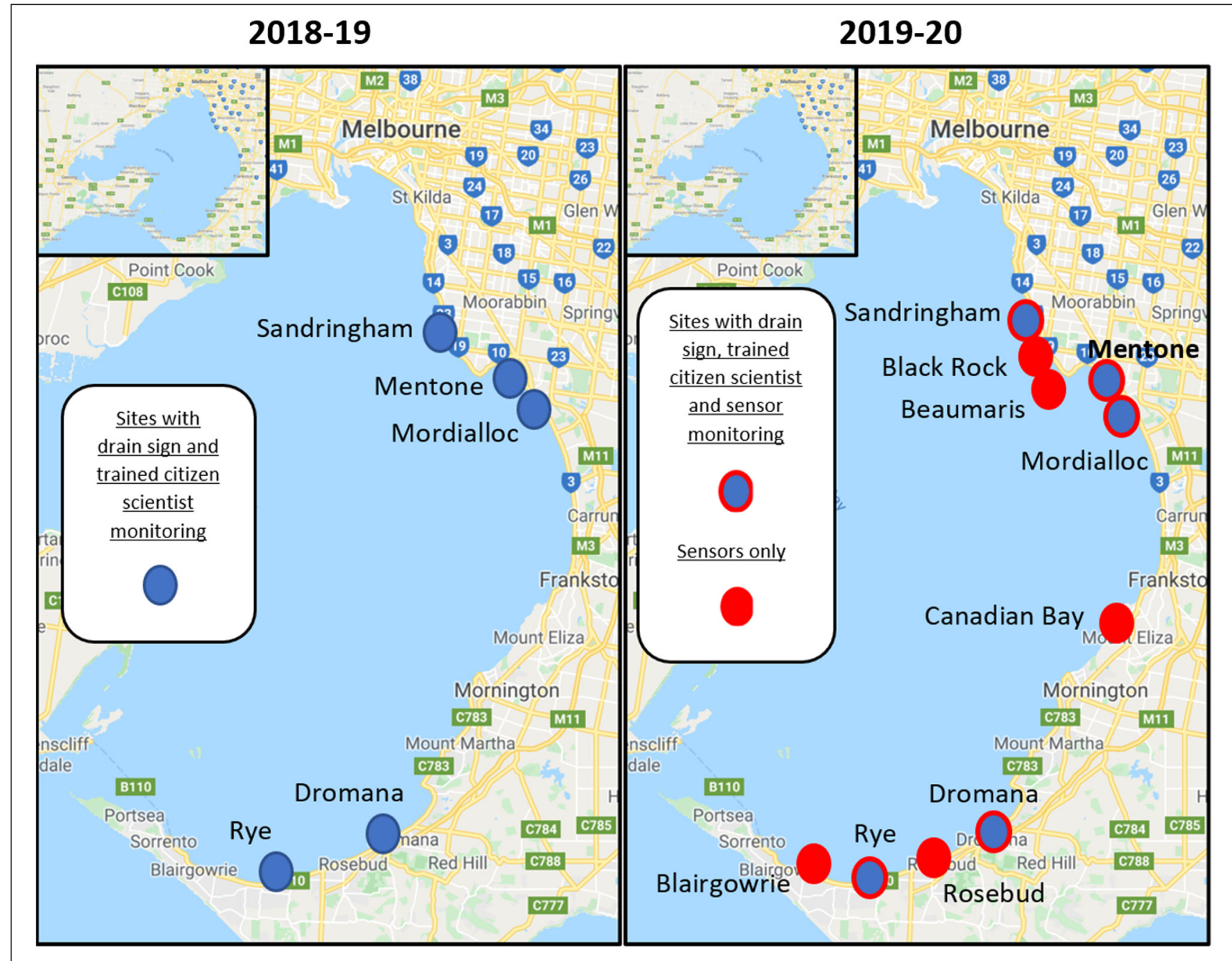

Figure 1 Location and type of monitoring at Drain Detective beaches in 2018-19 and 2019-20. 
were many drains not receiving enough citizen science reports to determine frequency and pattern of drain flows. By using the existing pool of citizen scientists to monitor fewer drains, it was envisioned that more meaningful data would be collected at these drains to better determine frequency and patterns of dry-weather flows.

\section{SIGNS AT STORMWATER DRAINS FOR COMMUNITY MONITORING}

The community could participate in Drain Detectives by using the drain monitoring instructional signs installed at five of the ten beaches in the project during the summer monitoring periods (year one: December 2018 through May 2019, and year two: December 2019 through March 2020). Signs for three beaches were designed by Life Saving Victoria. Different designs were tested and evaluated with a community user group to ensure they were fit for purpose. A council partner designed a sign for their two beaches in the project; this was preferred by the council to keep consistency with the design of their other signage on the foreshore.

At each of the five beaches, three signs were installed near a drain being targeted (i.e., fifteen signs in total). Signs were located at foreshore carparks, pathways close to the drain, and where possible, at the drain. Media articles, Tweets, and council newsletters were used for promoting the signs and to encourage community pollution reporting. All signs included a title, logos, a brief description of the project, and simple instructions for making a report using a smartphone, with reference to a data-collection platform for more information on how to locate the drain and what observations to make.

\section{TRAINED CITIZEN SCIENTIST MONITORING AT STORMWATER DRAINS}

Media articles, Twitter, and council newsletters were used for recruitment. The level of interest exceeded available places for citizen scientists in the Drain Detectives training program. Although the project had established a cap of 50 citizen scientists, 172 community members registered interest in participating. The response to the call for volunteers in year one highlighted the interest from the community to get involved in citizen science relating to beaches and water quality.

In total, the first 57 community members to register interest and 25 council officers were trained in drain monitoring. The number of trained volunteers could have been greater if resources permitted. People who registered Drain Detectives interest after the project cap was met were referred to the project's drain signs as another way they could get involved in the drain monitoring.
The 82 citizen scientists were provided with training to make drain flow observations and to conduct water quality monitoring. The water quality sampling involved the use of a simple test kit to analyse ammonia levels in drain water (API ammonia test kit). Ammonia was used as a general indicator of faecal pollution after successfully being used in previous drain flow investigations where it was sensitive enough to detect faecal pollution in high concentrations (e.g., sewer spill or significant leak) (Amos and Sharley 2016). The test was an easy addition to collecting visual observations, as the sample was easy and relatively safe to collect, and a result could be obtained onsite.

Group training of citizen scientists was held at each of the five beaches targeted. In the second year of the project, no additional citizen scientists were recruited because resource limitations forced a cap on the number that the project could support. Refresher training was provided for citizen scientists through a training video.

Trained citizen scientists were provided with a standard operating procedure with drain location maps and location codes (codes used in the data-collection platform to identify specific drains). The procedure also had instructions for using the form in the data-collection platform, for making observations, on occupational health and safety requirements, on taking informative field photos, and on collecting and analysing the ammonia test-kit samples in a safe manner.

In the first year of the project (2018-19), trained citizen scientists were asked to monitor drains on days and times that suited them. During the later stages of this monitoring period, better coordination of citizen science monitoring was trialled. Citizen scientists were asked to fill out a monitoring schedule of days and times, indicating their intentions to monitor. The purpose of the schedule was to avoid overlap of monitoring between citizen scientists and to obtain greater consistency in monitoring across days and times. In the second year of the project, more direction on when to monitor was provided to the citizen scientists from the start of the monitoring period (December 2019Mar 2020). Volunteers were emailed reminder requests to monitor drains when a week of dry weather was forecast, to target their monitoring efforts on periods that could provide the most useful data.

\section{SMARTPHONE MONITORING OF DRAINS}

Smartphones offered an ideal low-cost and readily available method for collecting data on whether drains were flowing. Smartphones allowed photos, written observations, and water quality data to be logged online by community reporters at drain signs and by the trained citizen scientists. 
When coupled with sensor monitoring, this provided an avenue to identify which drains were exhibiting regular dryweather flows.

\section{Online platform for data collection}

The online data-collection platform was Survey 123 for ArcGIS. This platform was compatible with EPA IT systems; had forms that could include the fields needed for photos, observations, and water quality results; was easy to use for citizen scientists via smartphone app or desktop; and had a database for storing data. The form was customised for citizen scientists and community reporters based on the type of user. The user would choose whether they were reporting drain flow from a sign or were a trained citizen scientist. The trained citizen scientist form included all drains being monitored and an extra field for ammonia test results.

Requested observations included whether the drain was flowing; a photo of the drain outlet showing the flow; the size, colour, and odour associated with the flow; whether the flow was reaching the bay; and if the flow was causing visible pollution.

\section{SENSOR MONITORING}

Depth, conductivity, and temperature sensors were used to determine the frequency and patterns of dry-weather flows at 10 beach drains. The depth sensor was used to detect elevated flows and provide information on flow size and frequency. Conductivity and temperature provided information on the water quality associated with flows (i.e., the possible presence of sewage). Sensors were tested and developed by Monash University for drain environments in year one of the project. Sensors were then installed at 10 beaches in the second year of the project, during summer.

\section{RESULTS}

Results for community reporting at drain signs and trained citizen science monitoring are described. These have been used to inform key learnings in this paper. Data collected by the community at drain signs and by trained citizen scientists is available in Supplemental File 1.

\section{SIGNS AT DRAINS FOR COMMUNITY MONITORING}

Signs enabled 49 community members, across the two years, to become involved in the project who otherwise may not have participated. Most community members who participated made a single report (e.g., photo and observations); repeat use of the signs by community members was uncommon.
Reports from signs made a valuable contribution to the total number of reports received. Reports from community members across the five drain signs made up 15\% and 16\% of total reports received in year one and two, respectively. The number of reports from signs varied considerably between the five beaches. The number of reports were noticeably higher at drains where signs were close to the drain, so photos and observations could be taken at the sign, and the beach was likely popular with foreshore or beach walkers.

\section{TRAINED CITIZEN SCIENTISTS}

Citizen scientists made 341 reports over the project duration. Data on drain flows was collected across sixteen drains at five beaches in 2018-19, and five drains at five beaches in 2019-20. The number of reports across drains was variable, with some drains getting a considerably higher number of reports than others. A good example of this was in 201819 , in which four drains received $44 \%$ of the reports over a six-month monitoring period (Figure 2). Not enough data was collected to determine definitive frequency of elevated flows, but the data was useful for indicating if there were continuous background flows, especially when combined with year-two data.

There was a decrease in the number of reports made between year one and two of the project (Figure 3). The average number of monthly reports decreased from 46 in 2018-19 to 15 in 2019-20. This decrease in reporting was consistent across sites and trained citizen scientists.

Most of the data was collected by a small proportion of trained citizen scientists. In year one, $36 \%$ of the citizen scientists who made reports were responsible for $82 \%$ of reports received. In year two, $44 \%$ of the citizen scientists who made reports were responsible for $71 \%$ of reports. Most trained citizen scientists either made no or only one report.

\section{KEY LEARNINGS}

Key learnings were developed from an evaluation of the Drain Detectives project, with a focus on those that could be used by others for better design and delivery of citizen science projects.

The approach of using citizen science and sensors was evaluated as effective for collecting the data needed to determine if there were drain flows during dry weather. Enough data was collected to assess what drains had continuous background flows; whether there were pulses of dry-weather flows; the frequency and size of flows; and whether flows were entering Port Phillip Bay. This data was used to target two drains for further investigation. More 


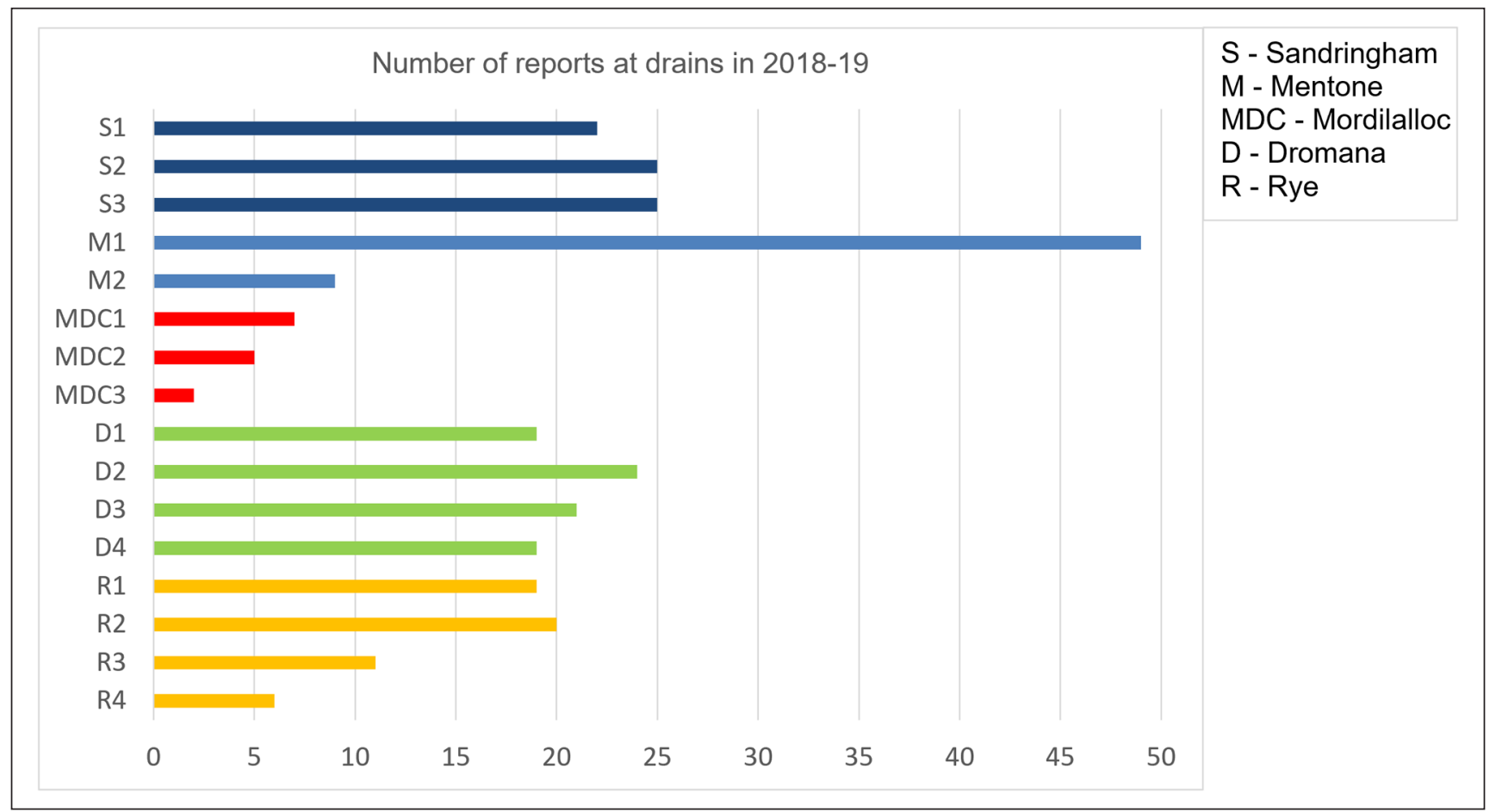

Figure 2 Number of reports at 16 drains monitored by trained citizen scientists in the 2018-19 six-month monitoring period.

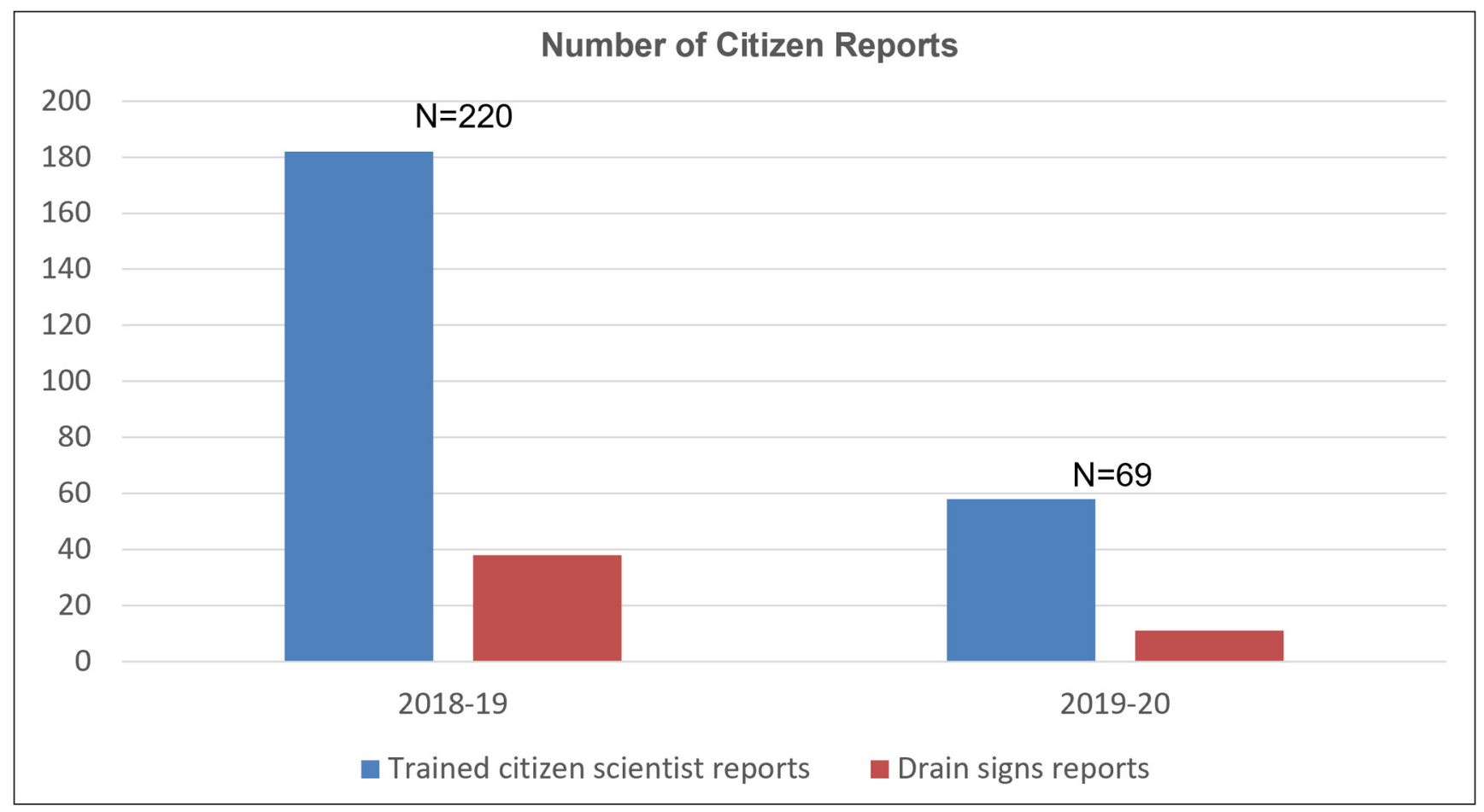

Figure 3 Number of citizen scientist reports from smartphone monitoring in year one and year two.

information on the way the data was used and water quality outcomes will be published in a separate paper. While useful data was collected, the monitoring approach using signs, citizen scientists, and sensors could have been better delivered to maximise data collected.

\section{CITIZEN SCIENCE DATA ENHANCED SENSOR MONITORING OF BEACH DRAINS}

The project fostered innovative science by using a combination of citizen science and sensors to monitor drains and to seek broad community participation in the 
project. No similar approach or project for water quality monitoring was evident in the literature.

The project demonstrated that trained citizen scientists with smartphones and a data-collection platform could regularly collect a range of data to support monitoring drains for water quality. The citizen science data enhanced sensor monitoring of drain flows, providing data on water colour, size of flow at outlet, ammonia levels, and whether flows were entering the Bay-data that could not be provided by sensors. Citizen science data was also good for indicating which drains had continuous background flows, whereas sensors were good for detecting and determining the extent of dry-weather pulses coming down drains.

Citizen science complemented the use of sensors. When data was combined from both sources over the two monitoring periods, a more complete set of data was available. For the five beaches with sensors and citizen science monitoring, the combined data was used to develop a risk profile for drains. The highest-risk drains were categorised as having continuous background flows or frequent pulses, with the dry-weather flows most likely entering the Bay. Continuous background flows were considered higher risk as they were most likely to occur during times people were swimming. Timing and size of pulses were also considered, with pulses occurring during daylight hours considered higher risk for people swimming. For the five beaches with sensors only, less data was available. The risk profiling was used to identify two drains that were potentially higher risk for swimmers. Further investigation with additional water quality sampling in the catchment of these drains identified the locations of previously unknown sources of dry-weather contamination sources. This was used by local authorities for targeted follow-up.

Citizen science addressed data gaps that came with using sensors in drains on their own, increasing the temporal and spatial scale of data collected. This finding was consistent with a variety of environmental monitoring in the literature (Lowry and Fienen 2013; Capdevila et al. 2020; Quinlivan, Chapman, and Sullivan 2020). Application of citizen science in Drain Detectives also enhanced what could be monitored, with citizen scientists collecting types of data that could not be provided by the sensors. Expansion of the type of data that can be collected as a result of citizen science has been demonstrated in water quality and in hydrological monitoring (Safford and Peters 2017; Starkey et al. 2017; Hegarty et al. 2021), as well as in monitoring of the Great Barrier Reef (Becken et al. 2019), with an emphasis on the value of combining citizen science and professionally collected data to better characterise the environment.

\section{IN-PERSON ENGAGEMENT AND REGULAR COMMUNICATION IS NEEDED TO MAXIMISE DATA COLLECTION}

The use of trained citizen scientists was successful at gathering a large amount of data. Most of the data was collected through the trained citizen scientists, complemented by data from the broader community using signs. However, during the evaluation of the project, it was recognised that more data could have been collected had more action been taken to reduce the variability in data collection between drain sites, years, and citizen scientists.

The variability in reporting between drains and citizen scientists (Sauermann and Franzoni 2015; Scott and Frost 2017; Weeser et al. 2018; De Moor, Rijpma, and Prats Lopez 2019) and a drop off in number of reports during the life of monitoring (Rotman et al. 2014; Sauermann and Franzoni 2015) is common in citizen science. For Drain Detectives, this may have been due to changes in personal circumstances of volunteers, to not enough in-person engagement and communication to maintain interest or motivation, to the number and location of drains, or to unfavourable weather.

Regular and diverse engagement is important for motivating and retaining citizen scientists (De Moor, Rijpma, and Prats Lopez 2019). Not enough resourcing was built into the Drain Detectives project to engage more actively in person with trained citizen scientists and to provide more regular communication and feedback. The EPA Citizen Science Program was in its early stages when this project was scoped, and the time needed and importance of in-person engagement and communications was underestimated.

The only in-person contact with citizen scientists throughout the project was through the training sessions in year one. After that, communication was mainly through emails and the Yarra and Bay website (which no longer exists). Gathering citizen scientists together yearly to discuss data quality, to get feedback on their experiences, and to discuss findings and next steps may have helped to maintain the motivation and participation of citizen scientists; however; this was not undertaken because of resource constraints. An online survey was conducted to see what engagement the citizen scientists preferred, but only a small number of trained citizen scientists responded, and there was a mixed response on whether further engagement was wanted. The location and spread of the beaches across Port Phillip Bay made gathering all citizen scientists for a single in-person engagement activity challenging, and having single events per beach would have required a large amount of resourcing. Inviting citizen scientists to nominate their preferred engagement method(s) could have been built into the training sessions 
at the start of the project to make sure that feedback from most, if not all, volunteers would have been received. Greater resourcing for engagement and communications may have motivated and retained citizen scientists to continue to make reports, particularly in year two of the project. It would have also allowed the recruitment of more citizen scientists if needed.

Numerous studies and literature reviews have focussed on the importance of a range of factors for success in citizen science monitoring, with motivation and retention of citizen scientists through the life of monitoring featuring prominently (Alender 2016; Baruch et al. 2016; Compas and Wade 2018; Capdevila et al. 2020). An organisation's communications and reporting back to citizen scientists, as well as in-person engagement and associated relationships, add to the experience of citizen scientists and their sense of making a valuable contribution (Kim et al. 2011; Alender 2016; Storey et al. 2016; Shupe 2017; Capdevila et al. 2020). This leads to citizen scientists being more likely to collect more data and stay engaged in the monitoring, resulting in a better outcome for citizen scientists and the project or monitoring program. Citizen science engagement and retention in a project can increase again if they are engaged in project co-design and co-interpretation (Shirk et al. 2012; Hidalgo et al. 2021).

Factoring the resources for in-person engagement and communications during the design phase of a project is important for getting the maximum amount of data and best outcomes for everyone involved.

\section{SIGNS ARE VALUABLE FOR DATA COLLECTION, BUT A RANGE OF FACTORS NEED TO BE CONSIDERED TO MAXIMISE THEIR USE}

The project demonstrated that data could be collected by untrained, local community members following directions on signs posted at drains. However, the value of this method for collecting a lot of data was limited by the low participation rate. This could be a limitation if signs are the sole method for data collection for a project. Low community engagement with signs placed at beaches and foreshore areas is not uncommon (Matthews, Andronaco, and Adams 2014; Morgan, Smith, and Matthews 2014; Rangsivek et al. 2019). Surveys (Morgan, Smith, and Matthews 2014) and anecdotal evidence within EPA regarding water quality signage indicate low awareness of signs and low transmission of important water quality information to the public, particularly in the early days of new signage. As Drain Detectives signs asked the community to participate in reporting drain flows causing pollution (i.e., a call for action), there was value in trialling whether the community would have a higher uptake for this type of sign versus the water quality signs mentioned above.
There was a low number of repeat users of the signs and highly variable use across sign locations. Variability may have been due to beach popularity and to the proximity of signs to the drain (with signs closer to drains getting higher use). These patterns of use were also found in hydrological monitoring using citizen science and signage, such as CrowdHydrology (Lowry et al. 2019).

There is a range of variables that may contribute to low sign use, such as beach use, sign location, other signs on the foreshore, sign design, and sign promotion. High-use coastal foreshores can contain a large number of bylaws, warnings, or amenity signs that look similar in design. An additional sign added to the foreshore may not attract much attention. Sign promotion was primarily through social media platforms such as Twitter and Facebook. Marketing was not available to boost awareness of the signs within the community. Promotion and marketing of citizen science projects is not an uncommon constraint within government-led citizen science projects (Roger, Turak, and Tegart 2019).

Another reason for the low uptake of the signs may have been the text-heavy design. Early in the project when signs were being designed, the team's preference was to have a satellite aerial map of drain location and a photo of the drain, with brief instructions on the sign. This is a similar design to that used by CoastSnap in New South Wales, Australia, which monitors beach erosion (Harley et al. 2019). Because there was a risk that maps and photos would not print clearly on signs, the text-heavy design was used for Drain Detectives. In addition, the signs required participants to use a shortened URL to access a data-collection platform to get instructions, maps, and photos to locate the nearby drain and instructions for how to make reports. A QR code was considered instead, but internal advice was that they were not commonly used, although QR codes may be more commonly used now because of their use during the COVID-19 pandemic. A map, photo, and QR code on the sign may have attracted more attention or made the signs more engaging than text-only signs, but there is no way of knowing if this would have resulted in greater sign uptake for this project.

Signs may also be more successful depending on the type of project and the location of signs. For example, signs may be better suited to projects asking the community for simple, quick-to-collect data such as a single photo while standing at a sign, such as CoastSnap (Harley et al. 2019) or CrowdHydrology (Lowry et al. 2019). Drain Detectives requested a lot more data from sign users than these projects, including a photo and a range of observations. In addition, signs for CoastSnap and CrowdHydrology were located at the point where photos had to be taken. Drain Detectives signs were not always located directly 
at the drains as this was not always possible in a beach environment. This meant that some signs required the community to locate and walk over to a drain, take a photo, and fill out a field form for observations. This level of effort to make a report may have contributed to the low number of reports received from some signs.

The experience of using signs for Drain Detectives highlighted that there are many factors to consider before implementing this method for collecting data from the community. Ensuring a low effort for each report may increase the likelihood that the community will opportunistically take a photo or make an observation at a sign.

\section{CONCLUSION}

Lessons that came out of this project can be used by others doing similar projects or can be used more broadly to support existing literature on the design and delivery of citizen science projects (Robinson et al. 2018; Capdevila et al. 2020).

The citizen science and sensors trialled for Drain Detectives enabled the collection of data needed to assess which drains were higher risk for dry-weather flows at beaches. This data could not have been collected from traditional monitoring using weekly sampling and laboratory analysis. An outcome from the Drain Detectives monitoring was the detection of two high risk drains, where further investigation identified previously unknown faecal pollution sources. These were targeted for action by local authorities.

A key lesson from the project was the value of citizen science for addressing data gaps and for enhancing monitoring by collecting data that other methods cannot provide. The value of the combined citizen science and sensor data became apparent when it came time to construct risk profiles for drains. Combined citizen science and sensor data was used to characterise the risk of flows according to whether flows were continuous or discrete, flow size, the water quality associated with flows, and whether flows were reaching the Bay. The importance of integrating citizen science and professionally collected data is well recognised in the literature for enhancing project and monitoring program outcomes (Resch 2013; Farnham et al. 2017; Fritz, Fonte, and See 2017; Safford and Peters 2017).

Another key lesson was to maximise the data collected by adequately resourcing in-person engagement and communication to motivate and retain citizen scientists. More resources allocated to in-person engagement and communication may have led to less variability in data collected between citizen scientists, between drains, and over the life of the project.

The importance of in-person engagement and communication in design and delivery is well documented in the literature (Robinson et al. 2018; Capdevila et al. 2020). The need for better planning and resourcing for citizen science monitoring was a valuable lesson for an organisation in which citizen science is not its core business. EPA is still in its early days of incorporating citizen science monitoring into established monitoring programs.

The use of signs to collect community data complemented data collected by trained citizen scientists. However, the quantity of community data from signs was lower than expected. Two projects in the literature that had some success using signs offered some insights for this. CoastSnap (Hartley et al. 2017) and CrowdHydrology (Lowry et al. 2017) requested simple, easy-to-collect data from the community that could be collected at the location of the sign. This was not the case for Drain Detectives and would be a key consideration if using signs again.

The citizen science and sensor monitoring used by Drain Detectives provided valuable insights for monitoring water pollution and engaging with the community about water quality and pollution. The approaches trialled and lessons learnt from this project will inform EPA in future applications of this type of citizen science monitoring.

\section{DATA ACCESSIBILITY STATEMENT}

Citizen science data is provided in a supplementary file to this paper. Researchers needing more information can contact the lead author.

\section{SUPPLEMENTAL FILE}

The supplemental file for this article can be found as follows:

- Supplemental File 1. Appendix A: Citizen Science Data-Drain signs and trained citizen scientists. DOI: https://doi.org/10.5334/cstp.383.s1

\section{ETHICS AND CONSENT}

All work with project volunteers was conducted in accordance with EPA's Citizen Science Program 2020-2023. 


\section{ACKNOWLEDGEMENTS}

EPA would like to thank all the trained volunteer citizen scientists from the community and councils, and community reporters at drain signs who monitored beach drains over two summers.

EPA would also like to thank the following for their contribution to the project: Troy Gallant, Kate Waller, Jessica Fleming, Martin O'Shaughnessy, Sonia Hegarty and Tom Rodgers from EPA; Regan East from Department of Environment, Land, Water and Planning; Harry Young; Patrick McCormick; Julian Donlen and Kirsten Friend from Bayside City Council; Emily Boucher and Brad Lewis from Kingston City Council; Harish Kirubakaran, Melissa Burrage, Brenda Lee, David King and Peter O'Brien from Mornington Peninsula Shire; Tiana Preston from Melbourne Water; Karen Jones and Matt McArthur from Port Phillip EcoCentre; Bernadette Matthews, Rob Andronaco and Rhiannon Birch from Life Saving Victoria; Victoria Perkins from Sandringham Beach Patrol: Gary Robertson from Safety Beach and Dromana Beach Patrol; Julie James from Rye Beach Patrol; Peter Kinsman from Rye Yacht Club; and Russell Brown from Hampton Sailing Club.

\section{FUNDING INFORMATION}

This project was funded by the Victorian Government's Port Phillip Bay Fund under Grant PPBF6020, Bayside City Council, Kingston City Council, Mornington Peninsula Shire and South East Water. Any opinions, findings, and conclusions or recommendations expressed in this material are those of the authors and do not necessarily reflect the views of those who funded the project.

\section{COMPETING INTERESTS}

The authors have no competing interests to declare.

\section{AUTHOR CONTRIBUTIONS}

All authors contributed to conception, design, community engagement, data collection, and peer review of the draft paper.

\section{AUTHOR AFFILIATIONS}

\section{Darren Cottam}

Environment Protection Authority Victoria, AU

\section{Camille McGuire}

Environment Protection Authority Victoria, AU

David Mossop (D) orcid.org/0000-0002-3479-2793

University of Tasmania, AU

Geraldine Davis

Environment Protection Authority Victoria, AU

Julian Donlen

Bayside City Council, AU

Kirsten Friend

Bayside City Council, AU

Brad Lewis

Kingston City Council, AU

Emily Boucher

Kingston City Council, AU

Harish Kirubakaran

Manningham City Council, AU

Rebecca Goulding

South East Water, AU

Dusan Jovanovic (D) orcid.org/0000-0002-3642-883X

University of Novi Sad, AU

David McCarthy (D) orcid.org/0000-0001-8845-6501

Monash University, AU

April Seymore (D) orcid.org/0000-0002-7345-6311

Port Phillip EcoCentre, AU

Caroline Martino

Environment Protection Authority Victoria, AU

Kelly Zuccala

Environment Protection Authority Victoria, AU

\section{REFERENCES}

Alender, B. 2016. Understanding volunteer motivations to participate in citizen science projects: a deeper look at water quality monitoring. Journal of Science Communication, 153: 1-19. DOI: https://doi. org/10.22323/2.15030204

Amos, C and Sharley, D. 2016. Frankston Microbial Sourcing 2015-2016. Centre for Aquatic Pollution Identification and Management Technical Report No. 66, Victoria, Australia: University of Melbourne.

Baruch, A, May, A and Yu, D. 2016. The motivations, enablers and barriers for voluntary participation in an online crowdsourcing platform. Computers in Human Behavior, 64: 923-931. DOI: https://doi.org/10.1016/j.chb.2016.07.039

Becken, S, Conolly, RM, Chen, J and Stantic, B. 2019. A hybrid is born: Integrating collective sensing, citizen science and professional monitoring of the environment. Ecological Informatics, 52: 35-45. DOI: https://doi.org/10.1016/j. ecoinf.2019.05.001

Capdevila, ASL, Kokimova, A, Sinha Ray, S, Avellán, T, Kim, J and Kirschke, S. 2020. Success factors for citizen science projects in water quality monitoring. Science of the Total 
Environment, 728: 1-17. DOI: https://doi.org/10.1016/j. scitotenv.2020.137843

Church, SP, Payne, LB, Peel, S and Prokopy, LS. 2018. Beyond Water Data: Benefits to Volunteers and to Local Water from a Citizen Science Program. Journal of Environmental Planning and Management, 62(2): 306-321. DOI: https://doi.org/10.108 0/09640568.2017.1415869

Compas, ED and Wade, S. 2018. Testing the waters: a demonstration of a novel water quality mapping system for citizen science groups. Citizen Science: Theory and Practice, 3(2): 6. DOI: https://doi.org/10.5334/cstp.124

De Moor, T, Rijpma, A and Prats López, M. 2019. Dynamics of engagement in citizen science: results from the "Yes, I do!" project. Citizen Science: Theory and Practice, 4(1): 38. DOI: https://doi.org/10.5334/cstp.212

Farnham, DJ, Gibson, RA, Hsueh, DY, McGillis, WR, Culligan, PJ, Zain, N and Buchanan, R. 2017. Citizen science-based water quality monitoring: constructing a large database to characterize the impacts of combined sewer overflow in New York City. Science of The Total Environment, 580: 168-177. DOI: https://doi.org/10.1016/j.scitotenv.2016.11.116

Fritz, S, Fonte, CC and See, L. 2017. The role of citizen science in Earth observation. Remote Sensing, 9(4): 357. DOI: https://doi. org/10.3390/rs9040357

Graham, EA, Henderson, S and Schloss, A. 2011. Using mobile phones to engage citizen scientists in research. Eos, 92(38): 313-315. DOI: https://doi.org/10.1029/2011E0380002

Harley, MD, Kinsela, MA, Sánchez-Garcia, E and Vos, K. 2019. Shoreline change mapping using crowd-sourced smartphone images. Coastal Engineering, 150: 175-189. DOI: https://doi. org/10.1016/j.coastaleng.2019.04.003

Hegarty, S, Hayes, A, Regan, F, Bishop, I and Clinton, R. 2021. Using citizen science to understand river water quality while filling data gaps to meet United Nations Sustainable Development Goal 6 objectives. Science of The Total Environment, 783: 146953. DOI: https://doi.org/10.1016/j. scitotenv.2021.146953

Hidalgo, ES, Perelló, J, Becker, F, Bonhoure, I, Legris, M and Cigarini, A. 2021. Participation and co-creation in citizen science. In: Vohland K. et al. (eds.) The Science of Citizen Science, 199. Springer, Cham. DOI: https://doi. org/10.1007/978-3-030-58278-4_11

Jalbert, K and Kinchy, AJ. 2015. Sense and influence: environmental monitoring tools and the power of citizen science. Journal of Environmental Policy and Planning, 18(3): 1-19. DOI: https://doi.org/10.1080/1523908X.2015.1100985

Jones, BL, Unsworth, RKF, McKenzie, LJ, Yoshida, RL and Cullen-Unsworth, LC. 2018. Crowdsourcing conservation: the role of citizen science in securing a future for seagrass. Marine Pollution Bulletin, 134: 210-215. DOI: https://doi.org/10.1016/j. marpolbul.2017.11.005
Jovanovic, S, Carrion, D and Brovelli, MA. 2019. Citizen science for water quality monitoring applying Foss. The International Archives of the Photogrammetry, Remote Sensing and Spatial Information Sciences, XLII-4/W14: 119-126. DOI: https://doi. org/10.5194/isprs-archives-XLII-4-W14-119-2019

Kim, S, Robson, C, Zimmerman, T, Pierce, J and Haber, EM. 2011. Creek Watch: Pairing Usefulness and Usability for Successful Citizen Science. In: Proceedings of the International Conference on Human Factors in Computing Systems, CHI 2011, Vancouver, BC, Canada, May 7-12, 2011, pp. 21252134. DOI: https://doi.org/10.1145/1978942.1979251

Lowry, CS and Fienen, MN. 2013. CrowdHydrology: crowdsourcing hydrologic data and engaging citizen scientists. Ground Water, 51(1): 151-6. DOI: https://doi.org/10.1111/j.17456584.2012.00956.x

Lowry, CS, Fienen, MN, Hall, DM and Stepenuck, KF. 2019. Growing pains of crowdsourced stream stage monitoring using mobile phones: the development of CrowdHydrology. Frontiers in Earth Science, 7: 128. DOI: https://doi.org/10.3389/ feart.2019.00128

Matthews, B, Andronaco, R and Adams, A. 2014. Warning signs at beaches: Do they work? Safety Science, 62: 312-318. DOI: https://doi.org/10.1016/j.ssci.2013.09.003

Morgan, DJ, Smith, LDG and Matthews, BL. 2014. Beach report signage testing, Melbourne, Australia, 1-19. BehaviourWorks Australia.

Pocock, MJO, Tweddle, JC, Savage, J, Robinson, LD and Roy, HE. 2017. The diversity and evolution of ecological and environmental citizen science. PLOS ONE, 12(4): e0172579. DOI: https://doi.org/10.1371/journal.pone.0172579

Quinlivan, L, Chapman, DV and Sullivan, T. 2020. Validating citizen science monitoring of ambient water quality for the United Nations sustainable development goals. Science of the Total Environment, 699: 134255. DOI: https://doi. org/10.1016/j.scitotenv.2019.134255

Rangsivek, K, Allpress, J, Osborne, B and Huang, T. 2019. Safeswim Impact Evaluation: Aucklanders' awareness and behaviour one year on. Research and Evaluation Unit Technical report 2019/026, Auckland Council, Auckland, New Zealand.

Resch, B. 2013. People as sensors and collective sensingcontextual observations complementing geo-sensor network measurements. In: Krisp, J (ed.), Progress in Location-Based Services, 391-406. Lecture Notes in Geoinformation and Cartography book series. Berlin, Heidelberg: Springer. DOI: https://doi.org/10.1007/978-3-642-34203-5_22

Robinson, LD, Cawthray, JL, West, SE, Bonn, A and Ansine, J. 2018. Ten principles of citizen science. In: Hecker, S, Haklay, M, Bowser, A, Makuch, Z, Vogel, J and Bonn, A. Citizen Science: Innovation in Open Science, Society and Policy, 1-23. London: UCL Press. DOI: https://doi. org/10.14324/111.9781787352339 
Roger, E, Tegart, P, Dowsett, R, Kinsela, MR, Harley, MD and Ortac, G. 2020. Maximising the potential for citizen science in New South Wales. Australian Zoologist, 40(3): 449-461. DOI: https://doi.org/10.7882/AZ.2019.023

Roger, E, Turak, E and Tegart, P. 2019. Adopting citizen science as a tool to enhance monitoring for an environment agency. Citizen Science: Theory and Practice, 4(1): 35. DOI: https://doi. org/10.5334/cstp.231

Rotman, D, Hammock, J, Preece, J, Hansen, D, Boston, C, Bowser, A and He, Y. 2014. Motivations affecting initial and long-term participation in citizen science projects in three countries. In: iConference 2014 Proceedings, 110-124. DOI: https://doi.org/10.9776/14054

Safford, H and Peters, CA. 2017. Citizen science for dissolved oxygen monitoring: case studies from Georgia and Rhode Island. Environmental Engineering Science, 35(4): 362-372. DOI: https://doi.org/10.1089/ees.2017.0218

Sauermann, H and Franzoni, C. 2015. Crowd science user contribution patterns and their implications. Proceedings of the National Academy of Sciences, 112(3): 679-684. DOI: https://doi.org/10.1073/pnas.1408907112

Scott, AB and Frost, PC. 2017. Monitoring water quality in Toronto's urban stormwater ponds: assessing participation rates and data quality of water sampling by citizen scientists in the FreshWater watch. Science of the Total Environment, 59(2), 738-744. DOI: https://doi.org/10.1016/j. scitotenv.2017.01.201
Shirk, JL, Ballard, HL, Wilderman, CC, Phillips, T, Wiggins, A, Jordan, R, McCallie, E, Minarchek, M, Lewenstein, BV, Krasny, ME and Bonney, R. 2012. Public participation in scientific research: a framework for deliberate design. Ecology and Society, 17(2): 29. DOI: https://doi.org/10.5751/ES-04705170229

Shupe, SM. 2017. High resolution stream water quality assessment in the Vancouver, British Columbia region: a citizen science study. Science of the Total Environment, 603-604, 745-759. DOI: https://doi.org/10.1016/j. scitotenv.2017.02.195

Starkey, E, Large, A, Quinn, P, Parkin, G, Gibson, C and Birkinshaw, S. 2017. Demonstrating the value of communitybased 'citizen science' observations for catchment modelling and characterisation. Journal of Hydrology, 548: 801-817. DOI: https://doi.org/10.1016/j.jhydrol.2017.03.019

Storey, RG, Wright-stow, A, Kin, E, Davies-colley, RJ and Stott, R. 2016. Volunteer stream monitoring: do the data quality and monitoring experience support increased community involvement in freshwater decision making? Ecology and Society, 21(4): 32. DOI: https://doi.org/10.5751/ES-08934210432

Weeser, B, Stenfert Kroese, J, Jacobs, SR, Njue, N, Kemboi, Z, Ran, $\mathbf{A}$ and Breuer, L. 2018. Citizen science pioneers in Kenya - a crowdsourced approach for hydrological monitoring. Science of the Total Environment, 631-632, 1590-1599. DOI: https://doi.org/10.1016/j.scitotenv.2018.03.130

TO CITE THIS ARTICLE:

Cottam, D, McGuire, C, Mossop, D, Davis, G, Donlen, J, Friend, K, Lewis, B, Boucher, E, Kirubakaran, H, Goulding, R, Jovanovic, D, McCarthy, D, Seymore, A, Martino, C and Zuccala, K. 2021. Drain Detectives: Lessons Learned from Citizen Science Monitoring of Beach Drains. Citizen Science: Theory and Practice, 6(1): 20, pp. 1-12. DOI: https://doi.org/10.5334/cstp.383

Submitted: 30 December 2020 Accepted: 13 August 2021 Published: 14 September2021

\section{COPYRIGHT:}

(C) 2021 The Author(s). This is an open-access article distributed under the terms of the Creative Commons Attribution 4.0 International License (CC-BY 4.0), which permits unrestricted use, distribution, and reproduction in any medium, provided the original author and source are credited. See http://creativecommons.org/licenses/by/4.0/.

Citizen Science: Theory and Practice is a peer-reviewed open access journal published by Ubiquity Press.

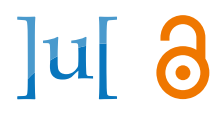

